\title{
A phase II study of the PI3K inhibitor copanlisib in combination with the anti- CD20 monoclonal antibody rituximab for patients with marginal zone lymphoma: treatment rationale and protocol design of the COUP-1 trial
}

Alexander Grunenberg ${ }^{1 *}$ (D, Lisa M. Kaiser², Stephanie Woelfle², Birgit Schmelzle², Andreas Viardot ${ }^{1}$, Peter Möller $^{3}$, Thomas F. E. Barth ${ }^{3}$, Rainer Muche ${ }^{4}$, Jens Dreyhaupt ${ }^{4}$, Markus Raderer $^{5}$, Barbara Kiesewetter ${ }^{5}$ and Christian Buske ${ }^{1}$

\begin{abstract}
Background: Advanced stage marginal zone lymphoma (MZL) is an incurable indolent B-cell lymphoma, for which a wide variety of treatments ranging from single agent rituximab to more dose intense immunochemotherapy exists. One of the major goals in this palliative setting is to develop chemotherapy-free treatments, which approach the efficacy of immunochemotherapies, but avoid chemotherapy associated toxicity in this often elderly patient population. The PI3K inhibitor copanlisib has recently shown remarkable clinical activity in refractory or relapsed indolent B-cell lymphomas, among them MZL. Based on these data, copanlisib monotherapy was granted breakthrough designation by the FDA for the treatment of adult patients with relapsed marginal zone lymphoma who have received at least two prior therapies. However, data are still limited in particular for MZL. Based on this, the COUP-1 trial aims at testing the toxicity and efficacy of copanlisib in combination with rituximab in treatment naive and relapsed MZL.
\end{abstract}

Methods: COUP-1 is a prospective, multicenter, single-arm, open-label, non-randomized phase II trial of 6 cycles (28 days cycle) of copanlisib $(60 \mathrm{mg}$ intravenous day $1,8,15)$ and rituximab $\left(375 \mathrm{mg} / \mathrm{m}^{2}\right.$ intravenous day 1$)$ in the induction phase followed by a maintenance phase of copanlisib (d1, d15 every 4 weeks for a maximum of 12 cycles) and rituximab ( $\mathrm{d} 1$ every 8 weeks for a maximum of 12 cycles) in patients aged $\geq 18$ years with previously untreated or relapsed MZL in need of treatment. A total of 56 patients are to be enrolled. Primary endpoint is the complete response (CR) rate determined 12 months after start of induction therapy. Secondary endpoints include the overall response (OR) rate, progression free survival (PFS), overall survival (OS), safety and patient related outcome with quality of life.

The study includes a translational bio-sampling program with the prospect to measure minimal residual disease.

* Correspondence: alexander.grunenberg@uniklinik-ulm.de 'Department of Internal Medicine III, University Hospital Ulm, Albert-Einstein-Allee 23, 89081 Ulm, Germany

Full list of author information is available at the end of the article

(c) The Author(s). 2021 Open Access This article is licensed under a Creative Commons Attribution 4.0 International License, which permits use, sharing, adaptation, distribution and reproduction in any medium or format, as long as you give appropriate credit to the original author(s) and the source, provide a link to the Creative Commons licence, and indicate if changes were made. The images or other third party material in this article are included in the article's Creative Commons licence, unless indicated otherwise in a credit line to the material. If material is not included in the article's Creative Commons licence and your intended use is not permitted by statutory regulation or exceeds the permitted use, you will need to obtain permission directly from the copyright holder. To view a copy of this licence, visit http://creativecommons.org/licenses/by/4.0/. The Creative Commons Public Domain Dedication waiver (http://creativecommons.org/publicdomain/zero/1.0/) applies to the data made available in this article, unless otherwise stated in a credit line to the data. 
The study was initiated in November 2019.

Discussion: The COUP-1 trial evaluates the efficacy and toxicity of the treatment of copanlisib in combination with rituximab in patients with MZL and additionally offers the chance for translational research in this heterogenous type of lymphoma.

Trial registration: ClinicalTrials.gov: NCT03474744. Registration date: 03/23/2018.

Keywords: Marginal zone lymphoma, PI3K inhibitor, Copanlisib, Rituximab

\section{Background}

\section{Marginal zone lymphoma}

According to the WHO classification marginal zone lymphoma (MZL) is defined as a group of indolent nonHodgkin lymphoma that accounts for about $10 \%$ of all B-cell lymphomas. MZL is a disease that includes three histological subtypes: splenic (SMZL), nodal (NMZL) and extranodal MZL (EMZL) with the latter tumor also known as mucosa-associated lymphoid tissue (MALT) lymphoma [1]. Although these subtypes share a similar immunophenotype, clinical and molecular characteristics as well as treatment approaches are distinct.

SMZL typically presents with enlargement of the spleen and bone marrow infiltration without or minimal peripheral lymphadenopathy. In SMZL, lymphocytosis is often an incidental finding, whereas anemia and thrombocytopenia are multifactorial features in advanced-stage disease due to bone marrow infiltration, hypersplenism and/or autoimmune phenomena. Definitive diagnosis of SMZL is based on splenectomy but is often made by combining diagnostic results of peripheral blood and bone marrow examination [2].

The clinical picture of NMZL often resembles the pattern of other nodal lymphomas, such as follicular lymphoma, and is characterized by the enlargement of peripheral, abdominal, and thoracic lymph nodes and is usually non-bulky. Diagnosis requires the exclusion of extranodal manifestations and splenic involvement [3].

The most common form is extranodal marginal zone lymphoma, which can occur in a large variety of different extranodal organs. It typically shows so-called lymphoepithelial lesions with epithelial invasion by clonal B cells and has only a low tendency to disseminate. MZL is often associated with either chronic infections as a result of chronic antigenic stimulation (e.g. Helicobacter pylori in gastric MZL lymphoma) or organ-related autoimmune diseases (e.g. Sjögren's syndrome or Hashimoto's thyreoiditis) [4].

\section{Therapeutic options for marginal zone lymphoma}

Due to the indolent course of disease, an initial watch and wait strategy in the asymptomatic patient can be recommended. If the patient is in need of treatment, there are basically three options including anti-infective (antibiotics, antiviral medication), local (surgery, radiotherapy) and systemic treatment approaches. However, treatment algorithms are mainly based on retrospective data or extrapolated from studies of other lymphoma subtypes. Partly, because of the heterogeneity and the relative rarity of each MZL subtype, conducting studies remain a particular challenge in this disease.

\section{Rituximab as a therapeutic strategy for MZL}

The CD20 antigen is expressed by B-lymphocytes on the surface of pre-B to the mature germinal center B-cells and the majority of mature B-cell neoplasia.

Rituximab targets specifically with high affinity $(5 \times$ $10^{-9} \mathrm{~mol} / \mathrm{L}$ ) the glycolysated transmembrane phosphoprotein CD20. Upon binding of the Fab-fragment of the antibody to the $\mathrm{CD} 20$ antigen the Fc-fragment mediates various immunological responses $(\mathrm{CDC}=$ complementdependent cytotoxicity, $\mathrm{ADCC}=$ antibody dependent cell-mediated cytotoxicity, $\mathrm{ADP}=$ antibody dependent phagocytosis) that contribute to the effective destruction of $\mathrm{CD} 20$ positive $\mathrm{B}$-cells and thereby is a promising target in MZL [5-9]. Apart from the immune mediated mechanisms CD20 bound rituximab can initiate direct signaling induced cell death through redistribution of CD20 to lipid rafts (membrane domains rich in cholesterol and sphingolipids) that affect cell membrane and intracellular signaling effects [10].

Rituximab monotherapy is well tolerated, safe and has a reasonable anti-lymphoma activity at least in SMZL and EMZL. According to a recently published meta-analysis, assessing the efficacy of rituximab monotherapy in MZL, best response rates are achieved in SMZL [11] (see Table 1). Rituximab efficacy can be further augmented by adding chemotherapy. The largest trial, the IELSG-19 trial,

Table 1 Efficacy data of rituximab monotherapy depending on MZL subtypes

\begin{tabular}{lllll}
\hline \multicolumn{2}{l}{ MZL subtype } & Number of patients & OR (\%) & CR (\%) \\
\hline EMZL & {$[11]$} & 112 & 73 & 45 \\
& {$[12]$} & 138 & 78 & 56 \\
SMZL [11] & 122 & 92 & 58 \\
NMZL [11] & 3 & 33 & 0 \\
\hline
\end{tabular}

MZL marginal zone lymphoma, EMZL extranodal marginal zone lymphoma, $S M Z L$ splenic marginal zone lymphoma, NMZL nodal marginal zone lymphoma, $O R$ overall response, $C R$ complete response 
randomized patients between chlorambucil, rituximab/chlorambucil and rituximab single agent in patients with no prior treatment of EMZL. In this trial, overall response (OR) rate was $78.3 \%$ with $55.8 \%$ complete response (CR) and $22.5 \%$ partial response (PR) for rituximab monotherapy compared with $94.7,78.8$ and $15.9 \%$, respectively, for rituximab/chlorambucil [12, 13]. However, depending on the type of selected treatment approach, immunochemotherapy can be associated with considerable morbidity (grade $\geq 3$ adverse events about $80 \%$ ) and mortality rate (up to $11.9 \%$ ) in MZL $[14,15]$.

\section{Copanlisib as a therapeutic strategy for MZL}

Nowadays, in the era of targeted medicine, small molecule inhibitors of kinases involved in B-cell signaling represent a promising area of research, including phosphatidylinositol-3-kinase (PI3K). PI3Ks are a family of heterodimeric kinases consisting of a catalytic and a regulatory subunit and are divided into three classes (class I, II and III). Four of these PI3K isoforms (PI3K $\alpha$, PI3K $\beta$, PI3K $\gamma$, PI3K $\delta$ ) are categorized as class I enzymes because they can use phosphatidylinositol 4,5-bisphosphonate (PIP2) to generate phosphatidylinositol 3,4,5-triphosphate (PIP3). Elevated PIP3 in cellular membranes drives several hallmarks of the cancer phenotype such as proliferation, survival, and immune regulation (Fig. 1)
[16]. PI3K $\alpha$ and PI3K $\beta$ are expressed ubiquitously, whereas $\mathrm{PI} 3 \mathrm{~K} \gamma$ and $\mathrm{PI} 3 \mathrm{~K} \delta$ are highly restricted to hematopoietic tissue. Copanlisib (Bay 80-6946) is a potent pan-class I PI3K inhibitor, with approximately tenfold preferential inhibition of the PI3K $\alpha$ and PI3K $\delta$ isoform [17]. In 2016, a first-in-human phase I study reported promising anti-tumor activity of copanlisib, particularly in a small cohort of patients with advanced stage pretreated follicular lymphoma [18]. In line with that, Dreyling and colleagues demonstrated remarkable efficacy and manageable toxicity in heavily pretreated patients with indolent lymphoma. The OR was $43.7 \%$ in the indolent cohort [19]. Recently, the results of the pivotal phase II CHRONOS-1 study have led to the approval of copanlisib by the FDA. In this study, 142 patients with relapsed or refractory indolent lymphoma after two or more lines of therapy were enrolled, among 23 patients with MZL. In this lymphoma subtype the OR was $70 \%$, including $9 \%$ with a CR and $61 \%$ with a PR (see Table 2) [21].

\section{Study rationale}

So far, there is no well-established standard treatment for patients with MZL and systemic treatment approaches range from rituximab monotherapy to more

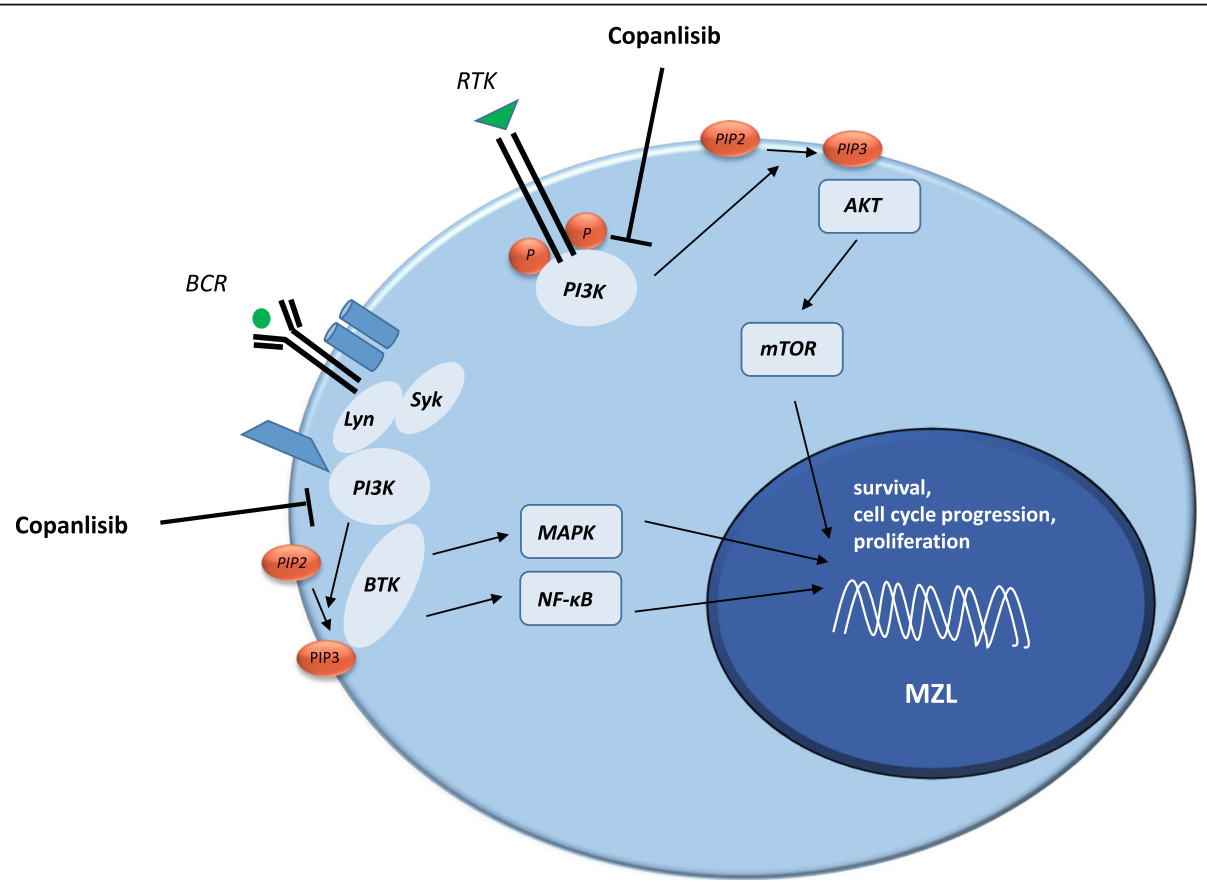

Fig. 1 PI3K signaling pathway in physiological and malignant B-cells. PI3K activity is regulated in both a B-cell receptor (BCR) and receptor tyrosine kinase (RTK) mode. Upon RTK stimulation PI3K catalyses phosphatidylinositol 4,5-bisphosphonate (PIP2) to generate phosphatidylinositol 3,4,5-triphosphate (PIP3), resulting in recruitment of AKT (Protein kinase B) and activation of the MTOR (mechanistic target of rapamycin) pathway. On the other hand, BCR stimulation leads to the recruitment of BTK (bruton tyrosine kinase) via PIP3 with downstream activation of the MAPK (mitogen-activated protein kinase) and NFkB (nuclear factor 'kappa-light-chain-enhancer' of activated B-cells) signaling pathway. Pathological triggering of both signaling pathways eventually results in increased proliferation and survival advantage of the B-cell. MZL = marginal zone lymphoma, Syk = spleen tyrosine kinase, Lyn = kinase 
Table 2 Selected data of copanlisib monotherapy in relapsed or refractory B-cell-lymphoma subtypes in clinical trials

\begin{tabular}{|c|c|c|c|c|c|}
\hline Trial & $\begin{array}{l}\text { Subtype of } \\
\text { lymphoma (\%) }\end{array}$ & $\begin{array}{l}\text { Number of } \\
\text { patients }\end{array}$ & OR (\%) & CR (\%) & $\begin{array}{l}\text { summary of treatment-emergent } \geq \text { grade } 3(\%) \text { occurring in } \\
\geq 10 \% \text { of the total population }\end{array}$ \\
\hline $\begin{array}{l}\text { Phase I } \\
{[18]}\end{array}$ & $\begin{array}{l}\mathrm{FL}(66.6), \mathrm{DLBCL} \\
(33.3)\end{array}$ & 9 & $78 \%$ & $11 \%$ & $\begin{array}{l}\text { hyperglycemia (33), hypertension (33), } \\
\text { lung infection (22), } \\
\text { neutropenia (11), } \\
\text { rash (11), } \\
\text { anemia (11) }\end{array}$ \\
\hline $\begin{array}{l}\text { Phase II } \\
{[20]}\end{array}$ & DLBCL (100) & 79 & 19.4 & 5 & hyperglycemia (33), hypertension (31) \\
\hline $\begin{array}{l}\text { Phase II } \\
{[21]}\end{array}$ & $\begin{array}{l}\text { FL (73), } \\
\text { MZL (16), } \\
\text { SLL } 8(6) \\
\text { LPL/WM (4), } \\
\text { DLBCL (1) }\end{array}$ & 142 & $\begin{array}{l}59 \text { (overall } \\
\text { cohort), } \\
70 \text { (only } \\
\text { MZL) }\end{array}$ & $\begin{array}{l}12 \text { (overall } \\
\text { cohort), } \\
9 \text { (only MZL) }\end{array}$ & $\begin{array}{l}\text { hyperglycemia (41), hypertension (24), } \\
\text { lung infection (15), } \\
\text { neutropenia (24) }\end{array}$ \\
\hline
\end{tabular}

FL follicular lymphoma, DLBCL diffuse large B-cell lymphoma, MZL marginal zone lymphoma, SLL small lymphocytic lymphoma, LPL lymphoplasmacytic lymphoma, WM Waldenström's macroglobulinemia, $O R$ overall response, $C R$ complete response

intense immunochemotherapy. The dilemma here is that data do not consistently show an advantage on patient's outcome with dose intense treatment. Moreover, it has to be taken into account that none of the dose intense approaches are regarded as curative and that the majority of patients suffering from MZL are elderly, highlighting the need to actively pursue safe and effective therapeutic options. Thus, mild chemotherapy-free approaches are highly attractive in this disease and the feasibility of this approach has been recently shown for the BTK inhibitor ibrutinib [22]. The hypothesis of this study is that adding copanlisib to rituximab is superior to rituximab monotherapy and is approaching the efficacy of immunochemotherapy without exposing the patient to chemotherapy associated toxicity.

\section{Methods and study design}

The COUP-1 is a multicenter, open label, single-arm phase II study. The objective of the trial is to test the efficacy and toxicity of the treatment of the combination of copanlisib and rituximab in patients with MZL in need of treatment, who have failed or are not eligible for local therapy or relapsed after local or systemic treatment. For efficacy the rate of complete remissions according to the GELA criteria for gastric MZL or to Cheson 2007 criteria for non-gastric extranodal, nodal and splenic MZL after induction therapy will be primary analysed. The trial is registered on the clinicaltrials.gov database (NCT03474744) and is conducted in accordance with the Declaration of Helsinki. The ethics committee of Ulm University approved the COUP-1 trial as leading ethics committee for all German sites. In addition, the leading Austrian ethics committee also approved the study.

\section{Key inclusion and exclusion criteria}

Eligible patients must be aged $\geq 18$ years, be able to provide written informed consent and must have a proven pathological diagnosis of either extranodal, nodal or splenic CD20-positive MZL, confirmed by a reference pathology center. Patients have to be in need of treatment and both treatment naïve and relapsed/refractory patients can be included. Treatment naïve patients have to be not eligible for local treatment or local treatment must have been failed in these patients. In patients with SMZL without splenic tissue available for histologic review, the diagnosis may be confirmed by the presence of splenomegaly and typical morphologic and immunophenotypic findings in the blood and bone marrow. At least one bi-dimensionally measurable lesion $(\geq 1.5 \mathrm{~cm})$ in its largest dimension by CT scan or MRI must be met. Of note, for gastric MZL, the clinical evidence of the MZL as seen by gastroendoscopy is sufficient. All patients should have adequate bone marrow function (neutrophil counts $\geq 0.75 \times 10^{9} / L$ or baseline platelet count $\geq 50 \times$ $10^{9} / L$ [if not due to bone marrow infiltration by the lymphoma], GFR $\geq 40 \mathrm{~mL} / \mathrm{min} / 1.73 \mathrm{~m}^{2}$, AST and ALT $\leq 3 \times$ upper limit of normal and bilirubin $\leq 2 \mathrm{mg} / \mathrm{dL}$ or $2 \times$ upper limit of normal).

Main exclusion criteria include ECOG $\geq 2$, CNS lymphoma, histologic evidence of transformation to a high grade or diffuse large B-cell lymphoma as well as chronic active hepatitis B. Ongoing immunosuppressive therapy including corticosteroids (exception < 4 weeks administered at a dose equivalent to $\leq 40 \mathrm{mg}$ /day prednisone is allowed) are not permitted. Additional exclusion criteria comprise an unstable or new-onset angina pectoris, myocardial infarction less than 6 months prior to test drug, congestive heart failure > class II, HbA1c > $8.5 \%$ and uncontrolled arterial hypertension despite optimal medical management.

\section{Treatment}

Patient enrollment started in November 2019. Eligible patients receive an induction phase of copanlisib and rituximab followed by a maintenance phase of each test 
drug (Fig. 2). The induction phase consists of six cycles ( 1 cycle $=28$ days). Copanlisib will be administered intravenously at a fix dose of $60 \mathrm{mg}$ on days $1,8,15$ of each cycle. Rituximab will be applied intravenously at a dose of $375 \mathrm{mg} / \mathrm{m}^{2}$ only on day 1 of each cycle.

Maintenance starts 2 months after the last induction cycle for patients at least achieving a stable disease after induction. During maintenance time copanlisib is administered at a dose of $60 \mathrm{mg}$ on days 1 and 15 every 4 weeks for a maximum of 12 cycles. Rituximab application is scheduled at a dose of $375 \mathrm{mg} / \mathrm{m}^{2}$ every 8 weeks for a maximum of $12 \mathrm{infu}-$ sions unless progression or study drug-related intolerable toxicity. In the follow-up phase, all subjects who enter the trial will continue to be followed every 3 months for disease progression, subsequent treatment and survival for 2 years after completion/discontinuation of treatment. Subsequently, patients will be monitored every 6 months for three additional years.

\section{Study objectives}

The objective of the trial is to test the efficacy and toxicity of treatment with copanlisib and rituximab in patients with MZL in need of treatment, who have failed, are not eligible for local therapy or relapsed. The primary end point of this study is the CR rate determined 12 months after start of induction therapy. For efficacy the rate of complete remissions according to the GELA criteria for gastric MZL or to the Cheson 2007 criteria for non-gastric extranodal, nodal and splenic MZL will be primarily analysed. Secondary efficacy end points include response rates (CR, PR and OR [CR or $\mathrm{PR}]$ ), best response, time to best response, time to first response, progression-free survival, time-to-treatment failure, remission duration, cause specific survival and overall survival. Quality of life assessment, based on the functional assessment of cancer therapy for lymphoma version 4 (FACT Lym) will be measured before start of treatment, during induction and maintenance.

\section{Safety analyses}

Safety variables include vital signs, physical examinations, evaluation of changes to concomitant medications, clinical laboratory parameters (hematology, serum chemistry), and the incidence, timing and severity of (serious) adverse events. The severity of adverse events will be graded using the CTCAE version 5.0 dictionary.

An independent external data safety monitoring committee (DSMC) will review ongoing safety data throughout the study. Review of the safety data by the DSMC will take place based on the safety analysis after the first 6 patients. In addition, a review will be performed when the 28th patient and the last patient has ended induction treatment. Following each meeting, the DSMC will prepare a report and may recommend changes in the conduct of the trial.

\section{Sample size calculation and statistical analysis}

In MZL a variety of treatment modalities are used. So far rituximab single agent is the most frequent chemotherapy-free approach used in this entity. Thus, a novel chemotherapy-free approach should be at least as efficient as rituximab monotherapy. In a large randomized trial rituximab monotherapy induced a CR of $55.8 \%$ compared to $78.8 \%$ for the combination of immunochemotherapy in treatment naïve EMZL subjects. CR rates in splenic MZL are comparable high at about $60 \%$, whereas $\mathrm{CR}$ rates in nodal MZL are reported a rare event. As the distribution of subtypes is about 70\% EMZL, $20 \%$ splenic and $10 \%$ nodal MZL, a CR which is better than $56 \%$ should at least be achieved by a new chemotherapy-free approach at 12 months after start of therapy.

For sample size calculation the one-sided one sample exact binomial test was used. According to the above data, the CR for the total group of the different subtypes must be better than $56 \% 12$ months after start of induction therapy. Based on a CR for copanlisib of about $75 \%$, a significance level of $2.5 \%$ (because of one-sided test) and a power of $80 \%, 48$ full evaluable patients will be necessary to show that the combination will be a promising candidate for challenging immunochemotherapy. It is expected, that the rate of withdrawal is smaller than $15 \%$. According to these parameters, the study is

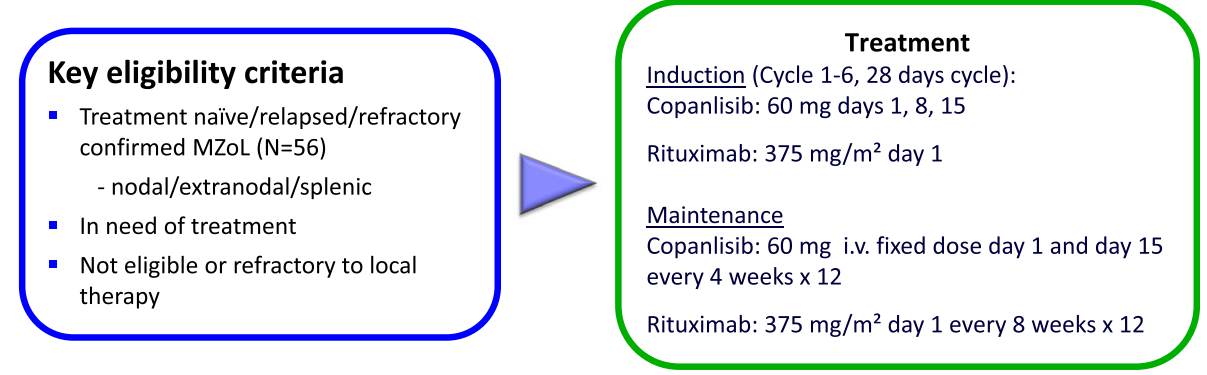

Fig. 2 Trial design. i.v. = intravenous 
planned to enroll 56 subjects. The distribution between the sexes is not relevant, because neither incidence of MZL differed between sexes nor clinically outcome measures have been shown to be related to sexes. The primary endpoint will be evaluated 12 months after the last patient recruited has started induction treatment. The primary parameter $\mathrm{CR}$ will be evaluated in a modified intention to treat way, which means that all patients for whom the primary endpoint $\mathrm{CR}$ is measured at 12 months after start of induction will be included in the analysis of the primary endpoint (core analysis population). This analysis population consists of all eligible patients included in the study who received at least one cycle of treatment. Patients without staging 12 months after start of treatment will be defined as non-responder $\left(\mathrm{CR}=\mathrm{NO}^{\prime}\right)$. Patients who progress before end of induction therapy will be regarded as treatment failure. No primary end point will be determined for patients who withdraw. These patients will be excluded from the confirmatory data analysis but will be analyzed in a separate exploratory sensitivity analysis of the primary end point.

The decision about the new dual treatment concept of copanlisib in combination with rituximab will be based on the one-sided one sample exact binomial test, using $\mathrm{CR} \leq 56 \%$ as $\mathrm{H} 0$. Thus, claim of success can be done if 36 (75\% of 48 patients) or more CR will be observed. Additionally, a one-sided $97.5 \%$ confidence interval for $\mathrm{CR}$ will be calculated as an effect estimator. Exploratory use of univariate logistic regression models will be performed to investigate the influence of putative risk factors associated with CR. Subgroup analysis in the subtype strata will be performed as further exploratory analysis. All secondary end points will be analyzed exploratory by respective descriptive analysis and $95 \%$ confidence intervals.

\section{Biosampling program}

The study includes a translational biosampling program which will serve as a platform for future research projects. The stored biospecimen program is a collection of serum, bone marrow and DNA specimens. Based on the study design, six eligible time points with sample collection prior to treatment, at the end of induction, at the primary endpoint (month 12), at the end of copanlisib treatment (month 20), at maintenance completion visit and in case of progression are defined (Fig. 3).

\section{Discussion}

We describe here an open-label, multicentric phase II trial to confirm the efficacy and safety of the combination of rituximab with copanlisib in MZL patients, who are either treatment naive or have relapsed/refractory disease. In this mostly elderly patient population, the development of chemotherapy-free approaches is of particular interest. However, complete response rates shown with target molecules given as a single agent are usual low and might be explained to the activation of additional pathways in resistant cases [22]. Thereby there is an urgent need to test combinations of compounds with complementary mode of action, ensuring long-lasting eradication of MZL cells. Indeed, combination testing deciphered several compounds, among them rituximab, that synergize with copanlisib in B-cell lymphoma models [23].

The PI3K $\delta$ inhibitor idelalisib was the first in its class to receive FDA approval in relapsed follicular lymphoma based on an overall response rate of $57 \%$ (CR 7\%) in double refractory patients. Similar results were reported for relapsed MZL patients (OR 47\%, no CR) [24]. However, early enthusiasm for this agent went down due to its toxicity profile and the drug subsequently gained a black box warning for adverse events such as hepatotoxicity, colitis, pneumonitis, and increased risk of opportunistic infections. Unexpected aggravation of adverse events in combined applications of idelalisib, including rituximab, even culminated in premature termination of trials and subsequently resulted in a restriction of its use despite the release of recommendations for the management of toxicity associated with idelalisib [25-27]. Copanlisib shows higher potency against all four PI3K

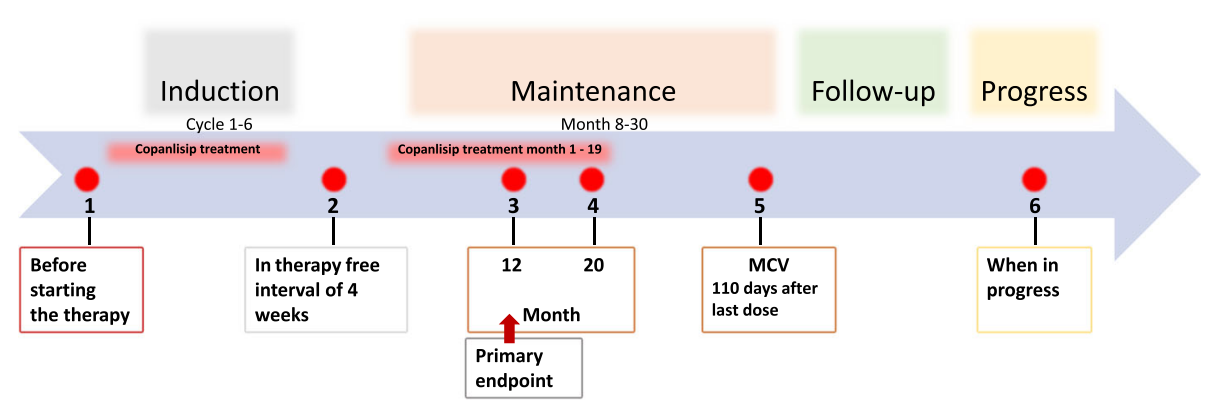

Fig. 3 Timeline of biomarker analyses of the COUP-1 trial 
class I isoforms and a more preferential targeting of the PI3K $\alpha$ compared to idelalisib and actually seems to have a more favorable safety profile, raising the possibility that side effects of selective PI3K $\delta$ inhibition might be avoided. The reported main side effects of copanlisib are mostly infusion-related including transient hyperglycemia, which is an expected on-target effect of PI3K $\alpha$ inhibition that is related to insulin-receptor signaling [28, 29]. Besides hyperglycemia, most common reported higher treatment-related adverse events are transient hypertension and neutropenia. Regarding the unique side effect profile of copanlisib, recommendations on optimal management of copanlisib associated adverse events have been recently published and will help to manage safe drug administration [30].

Based on the known activity and the favorable toxicity profile of rituximab as single agent and the promising efficacy results of copanlisib, the concept of this chemotherapy-free treatment approach is highly attractive and will help to define the role of this combination in MZL patients, aiming at challenging immmunochemotherapy. It will further help to evaluate the feasibility of rituximab/copanlisib maintenance therapy after induction in patients with MZL.

\section{Abbreviations}

ADCC: Antibody dependent cell-mediated cytotoxicity; ADP: Antibody dependent phagocytosis; BTK: Bruton tyrosine kinase; CD: Cluster of differentiation; CDC: Complement-dependent cytotoxicity; CNS: Central nervous system; CR: Complete response; CT: Computed tomography; CTCAE: Common Terminology Criteria for Adverse Events; DSMC: Data Safety Monitoring Committee; ECOG: Eastern Cooperative Oncology Group; EMZL: Extranodal marginal zone lymphoma; Fab: Fragment antigen-binding; FACT-Lym: Functional Assessment of Cancer Treatment-Lymphoma; Fc: Fragment crystallizable; FDA: Food and Drug Administration; GELA: Groupe d'Etude des Lymphomes de l'Adulte; GFR: Glomerular filtration rate; HbA1c: Hemoglobin A1c; H0: Null hypothesis; IELSG: International Extranodal Lymphoma Study Group; NMZL: Nodal marginal zone lymphoma; MRI: Magnetic resonance imaging; MZL: Marginal zone lymphoma; OR: Overall response; OS: Overall survival; PIP2: Phosphatidylinositol 4,5bisphosphonate; PIP3: Phosphatidylinositol 3,4,5-bisphosphonate; PI3K: Phosphatidylinositol-3-kinase; PFS: Progression free survival; PR: Partial response; SMZL: Splenic marginal zone lymphoma; WHO: World Health Organization

\section{Supplementary Information}

The online version contains supplementary material available at https://doi. org/10.1186/s12885-021-08464-6.

Additional file 1. SPIRIT (Standard Protocol Items: Recommendations for Interventional Trials) 2013 Checklist: Recommended items to address in a clinical trial protocol and related documents.

Additional file 2. Schedule of enrolment, interventions, and assessments.

\section{Acknowledgements}

The phase II trial started in 12/2019 and is still ongoing and recruiting patients. Further study information is open-access available at clinicaltrials. gov (NCT03474744).

\section{Authors' contributions}

$A G, C B, A V, M R$ and $B K$ developed and planned this trial and $C B$ is the principle investigator of the study. AG performed basic research and wrote the manuscript. PM and TFEB are conducting for reference pathology and diagnosis analysis. LMK coordinates an additional scientific program. RM and JD are the trial statistician and responsible for statistical planning and statistical analysis. SW and BS contributed in the trial design and modifications and data collection. All authors read and approved the final manuscript

\section{Funding}

The trial is partially supported by Bayer AG. Support includes the supply of the study medication. Celltrion Healthcare supplies study medication. There is no other funding of the trial. Data collection, analysis, interpretation of data and manuscript writing are independent form Bayer AG and Celltrion Healthcare. Open Access funding enabled and organized by Projekt DEAL.

\section{Availability of data and materials}

Not applicable.

\section{Declarations}

\section{Ethics approval and consent to participate}

The ethics committee of Ulm University approved the COUP-1 trial as leading ethics committee for all German sites. In addition, the leading Austrian ethics committee also approved the study. All patients signed informed consent according to GCP.

The trial is registered at clinicaltrials.gov (NCT03474744) and the European Clinical Trials Database (2017 EudraCT: 2017-003150-16). Protocol version: 4.0. (May 5th 2020).

\section{Consent for publication}

Not applicable.

\section{Competing interests}

Copanlisib and Rituximab are provided by Bayer AG and Celltrion Healthcare. The authors declare no conflicts of interest. The study was not externally reviewed. The authors have no financial relationship with Bayer AG or Celltrion Healthcare.

\section{Author details}

'Department of Internal Medicine III, University Hospital UIm, Albert-Einstein-Allee 23, 89081 UIm, Germany. ${ }^{2}$ Comprehensive Cancer Center UIm, Institute of Experimental Cancer Research, University Hospital Ulm, Albert-Einstein-Allee 23, 89081 UIm, Germany. ${ }^{3}$ Institute of Pathology, Ulm University, Albert-Einstein-Allee 23, 89081 Ulm, Germany. ${ }^{4}$ Institute of Epidemiology and Medical Biometry, UIm University, Schwabstraße 13, 89081 Ulm, Germany. ${ }^{5}$ Department of Medicine I, Division of Oncology, Medical University of Vienna, Vienna, Austria.

Received: 28 July 2020 Accepted: 9 June 2021

Published online: 29 June 2021

\section{References}

1. Swerdlow SH, Campo E, Pileri SA, Harris NL, Stein H, Siebert R, et al. The 2016 revision of the World Health Organization classification of lymphoid neoplasms. Blood. 2016;127(20):2375-90. https://doi.org/10.1182/blood-201 6-01-643569.

2. Arcaini $L$, Rossi $D$, Paulli M. Splenic marginal zone lymphoma: from genetics to management. Blood. 2016;127(17):2072-81. https://doi.org/10.1182/ blood-2015-11-624312.

3. Thieblemont C, Molina T, Davi F. Optimizing therapy for nodal marginal zone lymphoma. Blood. 2016;127(17):2064-71. https://doi.org/10.1182/ blood-2015-12-624296.

4. Zucca E, Bertoni F. The spectrum of MALT lymphoma at different sites: biological and therapeutic relevance. Blood. 2016;127(17):2082-92. https:// doi.org/10.1182/blood-2015-12-624304.

5. Maloney DG, Grillo-Lopez AJ, White CA, Bodkin D, Schilder RJ, Neidhart JA et al. IDEC-C2B8 (rituximab) anti-CD20 monoclonal antibody therapy in patients with relapsed low-grade non-Hodgkin's lymphoma. Blood. 1997; 90(6):2188-95. https://doi.org/10.1182/blood.V90.6.2188. 
6. Golay J, Introna M. Mechanism of action of therapeutic monoclonal antibodies: promises and pitfalls of in vitro and in vivo assays. Arch Biochem Biophys. 2012;526(2):146-53. https://doi.org/10.1016/j.abb.2012.02.011.

7. Beers SA, Cragg MS, Glennie MJ. Complement: help or hindrance? Blood. 2009;114(27):5567-8; author reply 5568. https://doi.org/10.1182/blood-2 009-10-249466.

8. Wang SY, Veeramani S, Racila E, Cagley J, Fritzinger DC, Vogel CW, et al. Depletion of the C3 component of complement enhances the ability of rituximab-coated target cells to activate human NK cells and improves the efficacy of monoclonal antibody therapy in an in vivo model. Blood. 2009; 114(26):5322-30. https://doi.org/10.1182/blood-2009-01-200469.

9. Wang W, Erbe AK, Hank JA, Morris ZS, Sondel PM. NK cell-mediated antibody-dependent cellular cytotoxicity in Cancer immunotherapy. Front Immunol. 2015;6:368.

10. Bezombes C, Fournie JJ, Laurent G. Direct effect of rituximab in B-cell-derived lymphoid neoplasias: mechanism, regulation, and perspectives. Mol Cancer Res. 2011;9(11):1435-42. https://doi.org/10.1158/1541-7786.MCR-11-0154.

11. Fuli F, Wei W, Guanglun L, Xiaoyan J, Xiaodan L, Xue S, et al. Efficacy and safety of rituximab in marginal zone lymphoma: a meta-analysis of 13 studies. Int J Clin Exp Med. 2016;9(8):17001-10.

12. Zucca E, Conconi A, Martinelli G, Bouabdallah R, Tucci A, Vitolo U, et al. Final results of the IELSG-19 randomized trial of mucosa-associated lymphoid tissue lymphoma: improved event-free and progression-free survival with rituximab plus Chlorambucil versus either Chlorambucil or rituximab monotherapy. J Clin Oncol. 2017;35(17):1905-12. https://doi.org/10.1200/ JCO.2016.70.6994

13. Zucca E, Conconi A, Laszlo D, Lopez-Guillermo A, Bouabdallah R, Coiffier B, et al. Addition of rituximab to chlorambucil produces superior event-free survival in the treatment of patients with extranodal marginal-zone B-cell lymphoma: 5-year analysis of the IELSG-19 randomized study. J Clin Oncol. 2013;31(5):565-72. https://doi.org/10.1200/JCO.2011.40.6272.

14. Herold M, Hoster E, Janssens A, McCarthy H, Tedeschi A, Pocock C, et al. Imunochemotherapy with Obinutuzumab or rituximab in a subset of patients in the randomised gallium trial with previously untreated marginal zone lymphoma (MZL). Hematol Oncol. 2017;35(S2):146-7. https://doi.org/1 0.1002/hon.2437 136.

15. Brown JR, Friedberg JW, Feng Y, Scofield S, Phillips K, Dal Cin P, et al. A phase 2 study of concurrent fludarabine and rituximab for the treatment of marginal zone lymphomas. Br J Haematol. 2009;145(6):741-8. https://doi. org/10.1111/j.1365-2141.2009.07677.x.

16. Cantley LC. The phosphoinositide 3-kinase pathway. Science. 2002; 296(5573):1655-7. https://doi.org/10.1126/science.296.5573.1655.

17. Liu N, Rowley BR, Bull CO, Schneider C, Haegebarth A, Schatz CA, et al. BAY 80-6946 is a highly selective intravenous PI3K inhibitor with potent p110alpha and p110delta activities in tumor cell lines and xenograft models. Mol Cancer Ther. 2013;12(11):2319-30. https://doi.org/10.1158/15357163.MCT-12-0993-T.

18. Patnaik A, Appleman LJ, Tolcher AW, Papadopoulos KP, Beeram M, Rasco DW, et al. First-in-human phase I study of copanlisib (BAY 80-6946), an intravenous pan-class I phosphatidylinositol 3-kinase inhibitor, in patients with advanced solid tumors and non-Hodgkin's lymphomas. Ann Oncol. 2016;27(10):1928-40. https://doi.org/10.1093/annonc/mdw282.

19. Dreyling M, Morschhauser F, Bouabdallah K, Bron D, Cunningham D, Assouline SE, et al. Phase II study of copanlisib, a PI3K inhibitor, in relapsed or refractory, indolent or aggressive lymphoma. Ann Oncol. 2017;28(9): 2169-78. https://doi.org/10.1093/annonc/mdx289.

20. Lenz G, Hawkes E, Verhoef G, Haioun C, Thye Lim S, Seog Heo D, et al Single-agent activity of phosphatidylinositol 3-kinase inhibition with copanlisib in patients with molecularly defined relapsed or refractory diffuse large B-cell lymphoma. Leukemia. 2020;34(8):2184-97. https://doi.org/10.103 8/s41375-020-0743-y.

21. Dreyling M, Santoro A, Mollica L, Leppa S, Follows GA, Lenz G, et al. Phosphatidylinositol 3-kinase inhibition by Copanlisib in relapsed or refractory indolent lymphoma. J Clin Oncol. 2017:35(35):3898-905. https:// doi.org/10.1200/JCO.2017.75.4648.

22. Noy A, de Vos S, Thieblemont C, Martin P, Flowers CR, Morschhauser F, et al. Targeting Bruton tyrosine kinase with ibrutinib in relapsed/refractory marginal zone lymphoma. Blood. 2017;129(16):2224-32. https://doi.org/1 0.1182/blood-2016-10-747345.

23. Tarantelli C, Lange M, Gaudio E, Cascione L, Spriano F, Kwee I, et al. Copanlisib synergizes with conventional and targeted agents including venetoclax in B- and T-cell lymphoma models. Blood Adv. 2020;4(5):819-29. https://doi.org/10.1182/bloodadvances.2019000844.

24. Gopal AK, Kahl BS, de Vos S, Wagner-Johnston ND, Schuster SJ, Jurczak WJ, et al. PI3Kdelta inhibition by idelalisib in patients with relapsed indolent lymphoma. N Engl J Med. 2014;370(11):1008-18. https://doi.org/10.1056/ NEJMoa1314583.

25. Cheah CY, Nastoupil LJ, Neelapu SS, Forbes SG, Oki Y, Fowler NH. Lenalidomide, idelalisib, and rituximab are unacceptably toxic in patients with relapsed/refractory indolent lymphoma. Blood. 2015;125(21):3357-9. https://doi.org/10.1182/blood-2015-03-633156.

26. Barr PM, Saylors GB, Spurgeon SE, Cheson BD, Greenwald DR, O'Brien SM, et al. Phase 2 study of idelalisib and entospletinib: pneumonitis limits combination therapy in relapsed refractory CLL and NHL. Blood. 2016; 127(20):2411-5. https://doi.org/10.1182/blood-2015-12-683516.

27. Cheah $\mathrm{CY}$, Fowler NH. Idelalisib in the management of lymphoma. Blood. 2016;128(3):331-6. https://doi.org/10.1182/blood-2016-02-702761.

28. Knight ZA, Gonzalez B, Feldman ME, Zunder ER, Goldenberg DD, Williams O, et al. A pharmacological map of the PI3-K family defines a role for p110alpha in insulin signaling. Cell. 2006;125(4):733-47. https://doi.org/10.1 016/j.cell.2006.03.035.

29. Krause G, Hassenruck F, Hallek M. Copanlisib for treatment of B-cell malignancies: the development of a PI3K inhibitor with considerable differences to idelalisib. Drug Des Devel Ther. 2018;12:2577-90. https://doi. org/10.2147/DDDT.S142406.

30. Cheson BD, O'Brien S, Ewer MS, Goncalves MD, Farooki A, Lenz G, et al. Optimal Management of Adverse Events from Copanlisib in the treatment of patients with non-Hodgkin lymphomas. Clin Lymphoma Myeloma Leuk. 2019;19(3):135-41. https://doi.org/10.1016/j.clml.2018.11.021.

\section{Publisher's Note}

Springer Nature remains neutral with regard to jurisdictional claims in published maps and institutional affiliations.

Ready to submit your research? Choose BMC and benefit from

- fast, convenient online submission

- thorough peer review by experienced researchers in your field

- rapid publication on acceptance

- support for research data, including large and complex data types

- gold Open Access which fosters wider collaboration and increased citations

- maximum visibility for your research: over $100 \mathrm{M}$ website views per year

At $\mathrm{BMC}$, research is always in progress.

Learn more biomedcentral.com/submissions 